\section{Case Reports in Ophthalmology}

Case Rep Ophthalmol 2017;8:489-495

DOI: $10.1159 / 000480724$

Published online: October 26, 2017
(C) 2017 The Author(s)

Published by S. Karger AG, Basel www.karger.com/cop

This article is licensed under the Creative Commons Attribution-NonCommercial 4.0 International License (CC BY-NC) (http://www.karger.com/Services/OpenAccessLicense). Usage and distribution for commercial purposes requires written permission.

\title{
Chronic Retinal Necrosis Severely Complicated by Neovascular Glaucoma: A Case Report
}

\author{
Takanori Matsuoka Kazunobu Asao Noriyasu Hashida Kohji Nishida \\ Department of Ophthalmology Osaka University Graduate School of Medicine, \\ Suita, Japan
}

\section{Keywords}

Chronic retinal necrosis - Immune insufficiency · Cytomegalovirus · Granular necrotizing retinitis - Neovascular glaucoma

\begin{abstract}
Background: Chronic retinal necrosis (CRN) is a rare chronic granular necrotizing retinitis that was first described in 2013. CRN is characterized by intraocular inflammation accompanied by occlusive vasculitis, granular retinitis, and slowly progressing necrosis around the retina in a host with partial immune dysfunction. Cytomegalovirus (CMV) is reported to be a causative agent. There are several ocular complications such as retinal detachment and neovascular glaucoma; however, there has been no description of a clinical manifestation of neovascular glaucoma in CRN. We herein present a case of severe neovascular glaucoma in association with CRN. Case Presentation: An 80-year-old man was referred to our hospital with poor control of inflammation and intraocular pressure (IOP). The IOP in his left eye was $29 \mathrm{~mm} \mathrm{Hg}$. Anterior chamber cells $(2+)$ and keratic precipitates were observed. In the peripheral retina, vitreous opacities and granular necrotizing retinitis were noticed. Fluorescein angiography revealed extensive retinal nonperfusion area from the macula lesion to the periphery. PCR analysis of aqueous humor showed the presence of CMV. A diagnosis of CRN was made soon afterwards. Antiviral drug and systemic corticosteroid were administered. The treatment temporally resolved the symptom; however, panretinal photocoagulation and intravitreal injection of bevacizumab were performed to treat iris neovascularization. During the follow-up, trabeculectomy was performed because of poor IOP control. At the final visit,
\end{abstract}




\section{Case Reports in Ophthalmology}

Case Rep Ophthalmol 2017;8:489-495

DOI: $10.1159 / 000480724$

(c) 2017 The Author(s). Published by S. Karger AG, Basel www.karger.com/cop

Matsuoka et al.: Chronic Retinal Necrosis Severely Complicated by Neovascular Glaucoma: A Case Report

severe uncontrolled neovascular glaucoma caused hyphema, and his left eye lost light perception. Conclusion: The prognosis of CRN is poor because of severe neovascular glaucoma and careful observation and active treatments are necessary.

(C) 2017 The Author(s)

Published by S. Karger AG, Basel

\section{Introduction}

There are several causes of intraocular inflammation, and infection-induced inflammation is caused by various microorganisms such as viruses, bacteria, and fungi [1]. Virus is the cause of infectious uveitis in many cases, and the causative virus includes herpes simplex virus (HSV), varicella-zoster virus (VZV), and cytomegalovirus (CMV) [1]. It may be determined by the immune state of the host, but some cases are treatment-resistant, and the prognosis of refractory uveitis is poor. In immunocompromised hosts, such as those infected with HIV, about $1 / 3$ of patients develop CMV retinitis, and many cases result in an ophthalmologically fatal outcome including life prognosis when host immunity does not improve [2].

Chronic retinal necrosis (CRN) is caused by CMV infection, and it was reported by Schneider et al. [3] in 2013. In non-HIV-infected immunocompetent hosts, it develops with immune dysfunction accompanying aging and diabetes, and the course prolongs compared with that of acute retinal necrosis (ARN) [3], and its clinical findings include intraocular inflammation accompanied by occlusive vasculitis around the retina, granular retinitis, and slowly progressing necrosis around the retina [3]. In ARN, clinical symptoms progress within a short time after the onset and rapidly advance to retinal detachment [4,5], whereas CRN progresses chronically [3]. Clinically, treatment should be immediately performed when either ARN or CRN is suspected, and intravenous administration of antiviral drugs and concomitant oral steroids are necessary [1, 3-5].

In CRN, neovascular glaucoma and retinal detachment occur after a long-term observation, similar to those in ARN, which may result in a poor outcome of vision. Thus, treatment should be chosen carefully. No study on CRN has been reported after the report by Schneider et al. [3], and to our knowledge, there has been no detailed report on CRN in Japan. In the current study, we report a case of CMV-induced CRN severely complicated by neovascular glaucoma and investigate the clinical characteristics of the disease.

\section{Case Report}

An 80-year-old man presented with blurred vision and visual loss in the left eye that persisted for about 6 months. The patient had been treated for uveitis-associated secondary glaucoma of the left eye by a local ophthalmologist for more than 10 years. The intraocular pressure (IOP) was well controlled with topical treatments, but inflammation became severe, and IOP control became poor. Trabeculotomy was performed in the left eye in 2010 . IOP elevation was noted since December 2012, and it was not improved by treatment. The patient was referred to our clinic. Past ocular medical histories were rhegmatogenous retinal detachment of the right eye treated with vitreous surgery and bilateral cataract operations. The patient was not an immunocompromised host infected by human immunodeficiency virus, nor was he treated with immunosuppressive drugs. Regarding the systemic complication, the patient had a past medical history of cerebral infarction. 


\section{Case Reports in Ophthalmology}

On the first examination, the best-corrected visual acuity (BCVA) was 30/20 in the right eye and 6/200 in the left eye, respectively. IOP was $19 \mathrm{~mm} \mathrm{Hg}$ in the right eye and $29 \mathrm{~mm} \mathrm{Hg}$ in the left eye. In the anterior chamber, keratic precipitates and cells $(2+)$ were observed in the left eye, but the right eye was normal (Fig. 1a, b). In the angle, no peripheral anterior synechia or pigmentation was noted, but neovascularization was observed in the angle and iris. On the fundus, the left eye flare was severe, vitreous opacity was noted, and the optic disc was pallor. In addition, granular white retinal lesions were present on the upper nasal side (Fig. 1c). No abnormal finding was observed in the right eye. On fluorescein fundus angiography (FA), contrast perfusion was noted only in the regions around the optic nerve and near the arcade, and an extensive nonperfusion area (NPA) was present around the retina (Fig. 1d). On indocyanine green FA, no finding suggested choroidal neovascularization. On high-penetration optical coherence tomography (swept source OCT: SS-OCT, DRI OCT-1 Atlantis; Topcon Corp., Japan), thinning of the outer layer and disturbance of the space in the inner layer and arrangement were noted in the retina on the temporal side over the macula in the left eye (Fig. 1e). No abnormality was observed in the right eye retina.

No abnormality was detected on blood testing or urinalysis including serum calcium, urinary calcium, and serum angiotensin-converting enzyme. On chest radiography, no finding suggested bilateral hilar lymphadenopathy. Regarding toxoplasmosis, syphilis, and intraocular lymphoma causing atypical retinal necrosis, exclusion diagnosis was performed by examining infections. CMV was positive on PCR tests of viral genomes in the aqueous humor of the anterior chamber. Based on the PCR test results and clinical findings, CMV-induced iritis and retinitis were diagnosed. Thus, valganciclovir $(1,800 \mathrm{mg} /$ daily $)$ with oral steroids $(20 \mathrm{mg} /$ daily) were administered. Inflammation decreased after initiation of oral treatment, and vitreous opacities and white retinal lesions tended to regress on fundoscopy; the steroid dose was then gradually reduced. Since the IOP was about 25-30 mm Hg during treatment with glaucoma eye drops, acetazolamide was additionally prescribed.

Since neovascular formations were present in the iris and angle, FA was performed, and extensive NPA was detected in the retia, for which retinal photocoagulation (PC) was initiated. Intravitreal bevacizumab injection was performed at the same time, aiming at regression of iris neovascularization, and it was effective. Additional PC was applied to NPA thereafter. For IOP control, treatment with glaucoma eye drops and oral acetazolamide was continued, but a high left IOP increased to $40 \mathrm{~mm} \mathrm{Hg}$. Thus, left eye trabeculectomy was performed in January 2013. After surgery, the IOP of the left eye decreased to $7 \mathrm{~mm} \mathrm{Hg}$. The pressure was maintained at a low level thereafter, and glaucoma eye drops were withdrawn. Vitreous opacities remained, but the fundus could be observed. The oral valganciclovir dose was reduced to $900 \mathrm{mg} /$ day, and the drug was then withdrawn. The condition could be maintained with $20 \mathrm{mg}$ /day of oral steroid. At 1 month after surgery, the left BCVA was 0.01, the left IOP was $7 \mathrm{~mm} \mathrm{Hg}$, and vitreous clouding remained only slightly on the fundus. At 4 months after surgery, the left BCVA was 0.01, and the left IOP moderately rose to $21 \mathrm{~mm} \mathrm{Hg}$, but the inflammation was mild and stable.

At 6 months after surgery, neovascularization of the iris and angle recurred (Fig. 2a, b), and vitreous hemorrhage was noted on fundoscopy (Fig. 2c). Topical treatments were restarted, and iris neovascularization was treated with intravitreous bevacizumab injection. However, the filtration bleb became nonfunctional due to new blood vessels, and the left IOP rose to $38 \mathrm{~mm} \mathrm{Hg}$. Vitreous surgery was investigated aiming at applying additional PC around the retina to treat retinal ischemia, but the patient did not agree and surgery was not performed. Since IOP control was poor, reconstruction of the left eye filtration bleb was repeated on August 9, 2013. The left IOP was maintained at about 5-10 mm Hg, and the patient 


\section{Case Reports in Ophthalmology}

Case Rep Ophthalmol 2017;8:489-495

DOI: $10.1159 / 000480724$

C 2017 The Author(s). Published by S. Karger AG, Basel www.karger.com/cop

Matsuoka et al.: Chronic Retinal Necrosis Severely Complicated by Neovascular Glaucoma: A Case Report

was referred to a local physician for follow-up. The patient developed IOP elevation again and was referred to our hospital. The left eye showed no light perception, the left IOP was 36 $\mathrm{mm} \mathrm{Hg}$, and hyphema was noted in the anterior chamber (Fig. 2d). Since it was painless, the expectation of visual acuity improvement was very low, and the systemic use of bevacizumab was accompanied by a risk, conservative treatment was selected in response to patient's request.

\section{Discussion}

CRN represents retinal necrosis caused by CMV infection. It develops in non-HIVinfected immunocompromised hosts with reduced immune function, which can be related to aging and diabetes, and it has been reported that aqueous humor in the anterior chamber is CMV-positive in all cases [3]. Its clinical findings include relatively moderate inflammation compared with that in ARN, occlusive vasculitis, and granular retinitis around the retina on the fundus, and slowly progressing necrosis around the retina [3]. The clinical course of ARN is acute and progressive, whereas CRN progresses slowly but irreversible changes chronically persist, finally resulting in a poor outcome because of neovascular glaucoma $[1$, 3-5]. In the current study, we reported a CRN patient, similar to previously reported cases, with severe complication with neovascular glaucoma, resulting in hyphema and poor IOP control.

We list differences in several clinical characteristics between the CRN of this patient and ARN. Firstly, the host immune state as patient background is different. ARN develops in persons with healthy immunity, but CRN develops in non-HIV-infected immunocompromised patients [1,3-5]. Secondly, the causative virus was VZV or HSV in many reported cases of ARN, whereas all CRN cases were reported to be CMV-positive [3]. In addition, on fundoscopy, expansion and fusion of yellowish-white exudate, vascular obstruction from the surrounding of the retina, and retinal necrosis are observed early after ARN onset, whereas extensive yellowish-white exudate and granular retinal lesions are observed in CRN, and extensive retinal ischemia is observed in the periphery of the retina on FA [1, 3-5]. Similar to previous reports, perfusion of fluorescence was localized in the optic nerve and near the arcade blood vessel in our patient [3]. Regarding treatment, many patients with ARN have poor outcomes due to retinal detachment and proliferative vitreoretinopathy despite intensive treatment [4-7]. In contrast, many patients with CRN develop neovascular glaucoma $(80 \%)$, but fewer patients develop retinal detachment (20\%). As previously reported, antiviral agents and oral steroid were administered, retinal PC was applied to the ischemic region, and iris neovascularization was treated with intravitreal anti-VEGF injection in our patient, but neovascular glaucoma developed, and the outcome of vision was poor [3].

When the grade of inflammation in viral retinitis is discussed, it is necessary to discuss the viral pathogenicity and the host's immune state. When viral pathogenicity is strong, such as that of VZV and HSV, and the host's immune state is favorable, strong immune reactions with pathogen may induce strong inflammatory reactions resulting in necrotic lesions observed in ARN [8-11]. On the other hand, in AIDS patients with markedly reduced immune function, it is assumed that although pathogen is the same, inflammatory reactions sufficient to attack the pathogen do not occur and only the outer layer of the retina is necrotized, resulting in progressive outer retinal necrosis [12]. In the pathogenesis of CRN, CMV-associated inflammation was very mild under the conditions with weak viral pathogenicity and a reduced immune state of the host $[13,14]$, but chronic inflammation led to 
Matsuoka et al.: Chronic Retinal Necrosis Severely Complicated by Neovascular Glaucoma: A Case Report

tissue hypoxia, and finally the patient developed neovascular glaucoma and hyphema. Severe uncontrolled glaucoma was usually observed in clinical courses as observed in the current case.

We reported a patient with CRN severely complicated by neovascular glaucoma. Its clinical manifestations included characteristic granular retinitis and the outer and inner layers of the retina impaired in the same period, and the advanced age and reduced immune function may have been involved in the pathology, as previously reported. Although the course is chronic, sometimes severe neovascular glaucoma develops, resulting in poor outcome. Careful observation and intensive treatments are necessary for the management of CRN.

\section{Statement of Ethics}

The patient provided written informed consent for the treatment. The study adhered to the tenets of the Declaration of Helsinki.

\section{Disclosure Statement}

The authors have no conflicts of interest to declare.

\section{References}

1 Ohguro N, Sonoda KH, Takeuchi M, Matsumura M, Mochizuki M: The 2009 prospective multi-center epidemiologic survey of uveitis in Japan. Jpn J Ophthalmol 2012;56:432-435.

2 Holland GN: AIDS and ophthalmology: the first quarter century. Am J Ophthalmol 2008;145:397-408.

-3 Schneider EW, Elner SG, van Kuijk FJ, Goldberg N, Lieberman RM, Eliott D, et al: Chronic retinal necrosis: cytomegalovirus necrotizing retinitis associated with panretinal vasculopathy in non-HIV patients. Retina 2013;33:1791-1799.

-4 Takase H, Okada AA, Goto H, Mizuki N, Namba K, Ohguro N, Sonoda KH, Tomita M, Keino H, Kezuka T, Kubono R, Mizuuchi K, Shibuya E, Takahashi H, Yanai R, Mochizuki M: Development and validation of new diagnostic criteria for acute retinal necrosis. Jpn J Ophthalmol 2015;59:14-20.

5 Holland GN: Standard diagnostic criteria for the acute retinal necrosis syndrome. Executive Committee of the American Uveitis Society. Am J Ophthalmol 1994;15:663-667.

-6 Taylor SR, Hamilton R, Hooper CY, Joshi L, Morarji J, Gupta N, et al: Valacyclovir in the treatment of acute retinal necrosis. BMC Ophthalmol 2012;12:48.

7 Usui Y, Goto H: Overview and diagnosis of acute retinal necrosis syndrome. Semin Ophthalmol 2008;23:275-283.

-8 Holland GN, Gottlieb MS, Yee RD, Schanker HM, Pettit TH: Ocular disorders associated with a new severe acquired cellular immunodeficiency syndrome. Am J Ophthalmol 1982;93:393-402.

-9 Kuppermann BD, Petty JG, Richman DD, Mathews WC, Fullerton SC, Rickman LS, Freeman WR: Correlation between CD4+ counts and prevalence of cytomegalovirus retinitis and human immunodeficiency virus-related noninfectious retinal vasculopathy in patients with acquired immunodeficiency syndrome. Am J Ophthalmol 1993;115:575-558.

10 Hsieh SM, Pan SC, Hung CC, Tsai HC, Chen MY, Chang SC: Association between cytomegalovirus-specific reactivity of $\mathrm{T}$ cell subsets and development of cytomegalovirus retinitis in patients with acquired immunodeficiency syndrome. J Infect Dis 2001;184:1386-1391.

-11 Lim WK, Chee SP, Nussenblatt RB: Progression of varicella-zoster virus necrotizing retinopathy in an HIV-negative patient with transient immune deviation. Graefes Arch Clin Exp Ophthalmol 2005;243:607-609.

-12 Engstrom RE Jr, Holland GN, Margolis TP, Muccioli C, Lindley JI, Belfort R Jr, Holland SP, Johnston WH, Wolitz RA, Kreiger AE: The progressive outer retinal necrosis syndrome. A variant of necrotizing herpetic retinopathy in patients with AIDS. Ophthalmology 1994;101:1488-1502. 


\section{Case Reports in \\ Ophthalmology}

\begin{tabular}{l|l}
\hline DOI: $10.1159 / 000480724$ & $\begin{array}{l}\text { C } 2017 \text { The Author(s). Published by S. Karger AG, Basel } \\
\text { www.karger.com/cop }\end{array}$ \\
\hline
\end{tabular}

Matsuoka et al.: Chronic Retinal Necrosis Severely Complicated by Neovascular Glaucoma: A Case Report

\footnotetext{
13 Woo JH, Lim WK, Ho SL, Teoh SC: Characteristics of cytomegalovirus uveitis in immunocompetent patients. Ocul Immunol Inflamm 2014;10:1-6.

14 Silverstein BE, Conrad D, Margolis TP, Wong IG: Cytomegalovirus-associated acute retinal necrosis syndrome. Am J Ophthalmol 1997;123:257-258.
}

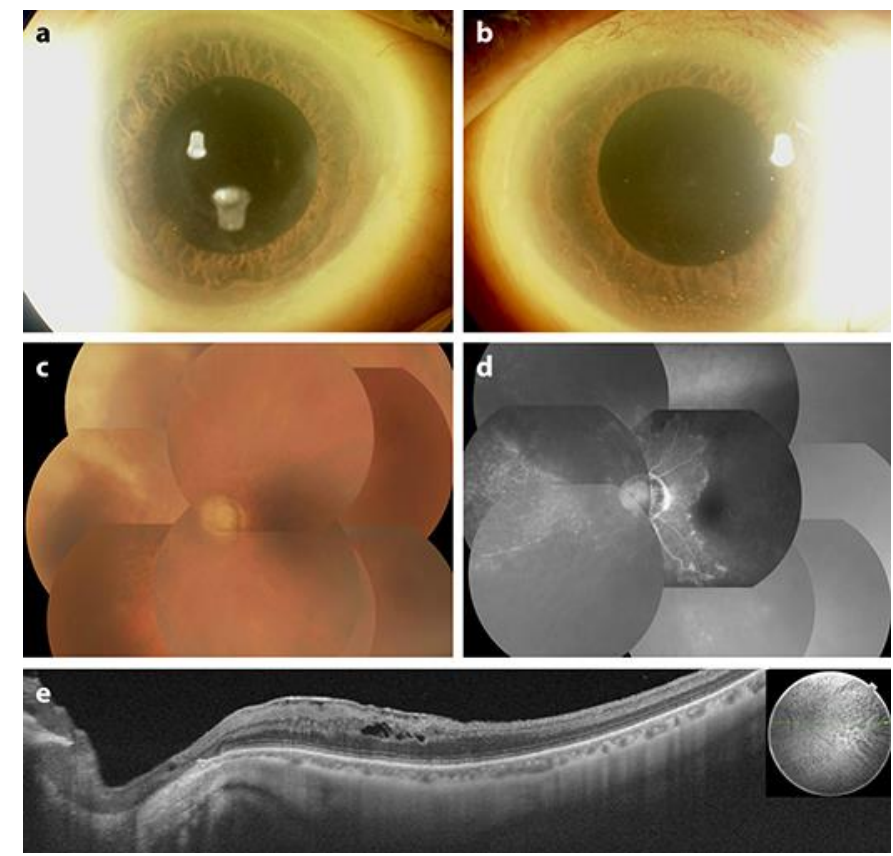

Fig. 1. a, b In the anterior chamber, keratic precipitates and cells were observed in the left eye, but the right eye was normal. c On the fundus, the optic disc was pallor, and granular white retinal lesions were present on the upper nasal side. $\mathbf{d}$ On fluorescein fundus angiography, contrast perfusion was noted only in the regions around the optic nerve and near the arcade, and an extensive nonperfusion area was present around the retina. e On high-penetration optical coherence tomography of the left eye, thinning of the outer layer and disturbance of the space in the inner layer and arrangement were noted in the retina on the temporal side over the macula. 
Case Reports in
Ophthalmology Case Rep Ophthalmol 2017;8:489-495 DOI: $10.1159 / 000480724$

(C) 2017 The Author(s). Published by S. Karger AG, Basel www.karger.com/cop

Matsuoka et al.: Chronic Retinal Necrosis Severely Complicated by Neovascular Glaucoma: A Case Report
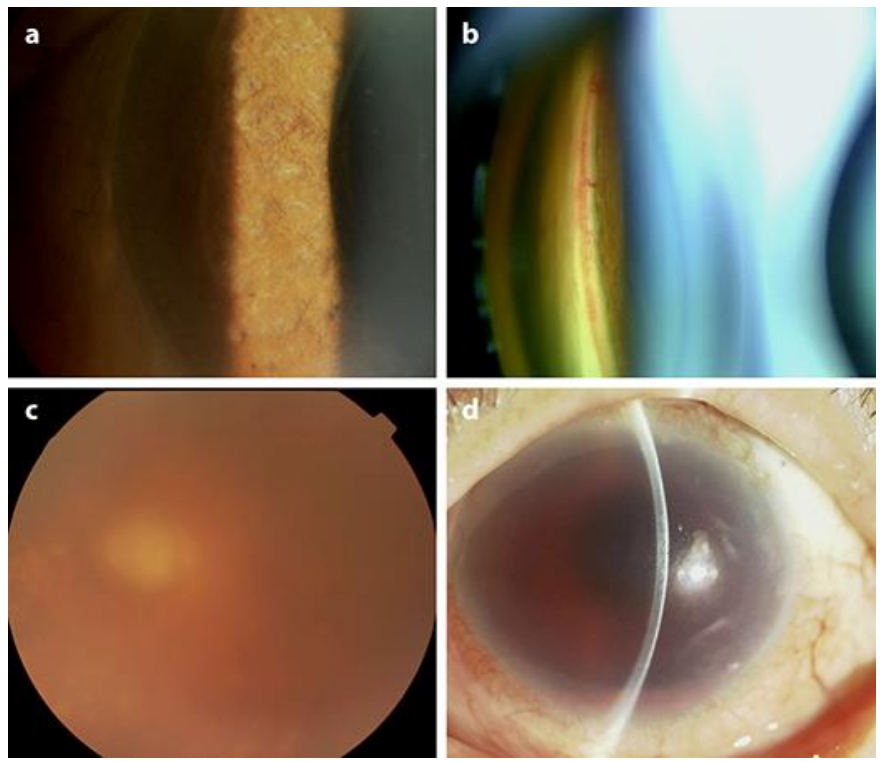

Fig. 2. Neovascularization of the iris and angle recurred (a, b), and vitreous hemorrhage was noted on funduscopy (c). d After an increase in intraocular pressure, hemorrhage was noted in the anterior chamber. 